\title{
A lifestyle management programme focused on exercise, diet and physiotherapy support for patients with hip or knee osteoarthritis and a body mass index over 35: a qualitative study
}

Law, Rebecca-Jane; Nafees, Sadia; Hiscock, Julia; Wynne, Cathy; Williams, Nefyn

\section{Musculoskeletal Care}

DOI:

$10.1002 / \mathrm{msc} .1382$

Published: 01/03/2019

Peer reviewed version

Cyswllt i'r cyhoeddiad / Link to publication

Dyfyniad o'r fersiwn a gyhoeddwyd / Citation for published version (APA):

Law, R-J., Nafees, S., Hiscock, J., Wynne, C., \& Williams, N. (2019). A lifestyle management programme focused on exercise, diet and physiotherapy support for patients with hip or knee osteoarthritis and a body mass index over 35: a qualitative study. Musculoskeletal Care, 17(1), 145-151. https://doi.org/10.1002/msc.1382

\footnotetext{
Hawliau Cyffredinol / General rights

Copyright and moral rights for the publications made accessible in the public portal are retained by the authors and/or other copyright owners and it is a condition of accessing publications that users recognise and abide by the legal requirements associated with these rights.

- Users may download and print one copy of any publication from the public portal for the purpose of private study or research.

- You may not further distribute the material or use it for any profit-making activity or commercial gain

- You may freely distribute the URL identifying the publication in the public portal ?
}

Take down policy

If you believe that this document breaches copyright please contact us providing details, and we will remove access to the work immediately and investigate your claim. 
Title: A lifestyle management programme focused on exercise, diet and physiotherapy support for patients with hip or knee osteoarthritis and a body mass index over 35: a qualitative study

Short running title: Lifestyle management for osteoarthritis

\section{Authors:}

Rebecca-Jane Lawa

Sadia Nafees ${ }^{a}$

Julia Hiscock ${ }^{\mathrm{a}}$

Cathy Wynneb

Nefyn Howard Williamsa*

\section{Affiliations:}

a) North Wales Centre for Primary Care Research, Bangor Institute for Health and Medical Research, Bangor University, Cambrian House 2, Wrexham Technology Park, Wrexham, UK

b) Physiotherapy Department, Betsi Cadwaladr University Health Board, Ysbyty Alltwen, Porthmadog, UK

For correspondence: Dr R Law, North Wales Centre for Primary Care Research, Bangor University, Cambrian House, Wrexham Technology Park, Wrexham, LL13 7YP, Email: r.law@bangor.ac.uk

Acknowledgements: We would like to thank all participants for their valuable contribution to this study. We are also grateful to Philip Bell (PB) for his valuable insight from a public and patient perspective during development of the study materials. Sources of funding: This study was supported by funding from Public Health Wales.

Conflict of interest statement: Cathy Wynne is a lead physiotherapist for the Lifestyle Management Programme and Associate Clinical Lead of Operations of Clinical Musculoskeletal Assessment and Triage Service (CMATS). Professor Nefyn Williams is a GP and was Director of Research and Development at Betsi Cadwaladr University Health Board at the time of this study. For the remaining authors none were declared. 
Lifestyle management for osteoarthritis

*Footnote:

Current affiliation of Nefyn Howard Williams: Department of Health Services Research, Room 105, 1st Floor, Block B, Waterhouse Building, 1-5 Brownlow Street, Liverpool, UK.

Current affiliation of Sadia Nafees: Centre for Mental Health and Society, Bangor University, Wrexham Technology Park. 
Lifestyle management for osteoarthritis

Title: A lifestyle management programme focused on exercise, diet and physiotherapy support for patients with hip or knee osteoarthritis and a body mass index over 35: a qualitative study.

\section{Abstract}

The Lifestyle Management Programme (LMP) is an exercise and weight management programme with physiotherapy support for people with hip or knee osteoarthritis $(O A)$ and a body mass index over 35 . This qualitative study explored views and experiences of the LMP amongst patients and professionals and offers insight for future programmes. Five referring clinicians and six delivering professionals participated in focus groups. Three referring GPs and nine patients who attended the LMP took part in semi-structured interviews. Topics included: referral, reasons for taking up and continuing the programme or not, and experiences and outcomes. Framework method was used to analyse the qualitative data. Overall, patients and professionals valued the multidisciplinary nature of the LMP. However, professionals explained feeling guilty about delaying patients on the orthopaedic waiting list and believed the programme should be re-directed to those with less severe OA and a lower BMI. Referring clinicians differed in their interpretation of the referral criteria and expressed varying levels of autonomy when making referrals. Patients referred after a consultation with their GP appeared more satisfied with the referral process. Patients were also encouraged by the opportunity to improve health, their likelihood of surgery and social benefits. However, patients were discouraged by inconvenience, cost, lack of readiness to change and embarrassment. In conclusion, shared decision-making about lifestyle management without delaying orthopaedic opinion is preferable, and more psychological support may increase participation. Importantly, the programme may be better focussed on rehabilitation for patients with a lower BMI and less severe symptoms.

Keywords: Osteoarthritis, Exercise, Dietetics, Body mass index, Health behaviour, Qualitative 
Lifestyle management for osteoarthritis

\section{Background}

Hip and knee osteoarthritis $(\mathrm{OA})$ is a common cause of pain and disability. Current guidelines from the UK National Institute of Clinical Excellence (NICE) recommend exercise and weight loss as core management principles (National Institute for Health and Care Excellence, 2014), with National Health Service organisations across the UK offering different schemes and pathways to meet these recommendations. One example is the Lifestyle Management Programme (LMP) where patients with pain and functional limitation from OA of the hip or knee and with a body mass index (BMI) greater than 35 are triaged and referred into a weight management and exercise programme with physiotherapy support; unless they are excluded for clinical reasons such as severe pain, functional limitation or joint deterioration. The LMP has four aims: 1) to improve musculoskeletal and general health, 2) to ensure that patients are in an optimum condition to undergo surgery should it be needed, 3) to reduce the BMI to less than or equal to 35 , and 4 ) to reduce the overall cost of elective orthopaedic pathways. The programme consists of a physiotherapy assessment at a participating leisure centre, followed by weekly group exercise sessions led by the National Exercise Referral Scheme (NERS) (Murphy et al., 2012) with physiotherapy support for 32 weeks, including an eight-week weight loss programme led by a qualified dietician. Patients reaching $10 \%$ weight loss or a BMI of 35 or below, and whose troublesome symptoms persist, are then referred for orthopaedic surgical opinion. For patients not meeting the required weight loss, a multidisciplinary team consider whether the patient is listed. Although the programme formed part of a re-design of the orthopaedic referral pathway, rather than a rehabilitation intervention, patients meeting the criteria can also be referred directly to the programme by their GP.

A previous service evaluation of the LMP (Williams et al., 2015, unpublished) observed small, nonsignificant improvements in BMI, body weight, and hip and knee function scores. However whilst $87 \%$ attended the first session, this dropped sharply to $14 \%$ at 32 weeks, but the reasons for poor levels of retention were not investigated. Therefore, the purpose of this study was to explore the experiences and views of both patients and professionals regarding the programme, and offer advice and recommendations relevant to the management of hip and knee $\mathrm{OA}$ in primary care. 
Lifestyle management for osteoarthritis

\section{Methods}

\section{Participants and recruitment}

The study population consisted of patients who had been referred to the LMP and professionals involved in referring to and delivering the programme. Patients were identified through LMP records and were purposively sampled according to age, gender and degree of uptake including; 'completers' who had attended regular sessions throughout the 32 week period including the final assessment session; 'partial attenders' who had attended for approximately half the time period but did not attend the final session and 'non-uptake' patients who were invited to the LMP but did not attend any sessions. Potential participants were sent invitations from the LMP clinical team by post and those willing to participate contacted the study team to arrange an individual interview.

Referring clinicians (triaging clinicians and physiotherapists) and delivering professionals (exercise professionals, physiotherapists and dieticians) were invited to participate in two separate focus groups. Referring GPs were invited to participate in individual telephone interviews. Professionals were recruited by email advertisement to local programme coordinators, physiotherapists, dieticians, GPs and clinicians involved in the scheme. Purposive sampling was used to encourage participation from varying levels of seniority, experience referring patients to LMP and location.

\section{Data collection}

Data was collected between February and April 2016 by the project team (RL, SN and JH). Focus groups and individual interviews were conducted using semi-structured topic guides including relevant prompts and probes. The development of the topic guides was guided by the study aims and objectives and refined through an iterative process involving the multidisciplinary study team $(R L, S N, J H, C W$, NW), with additional insight from a public and patient perspective (PB). The areas covered were; experiences of referral, helping and hindering factors, uptake and continuation of the programme (or not), and outcomes of the programme (see Appendix 1).

Focus groups were used for the referring and delivering professionals in order to benefit from participants interacting with each other and enable new perspectives to emerge about a common subject (Kitzinger, 1995). Focus groups lasted $90-120$ minutes and were conducted at an appropriate work-based location. For patients, individual interviews were used as it was felt that the nature of the 
Lifestyle management for osteoarthritis

responses may be more personal and therefore individual accounts were sought. This type of data collection also allowed the participant to identify a time and location convenient to them. Therefore individual interviews were also chosen for GPs as they had limited time. Individual interviews lasted a maximum of 60 minutes. Patient interviews were conducted on university premises and GP interviews took place over the telephone.

\section{Qualitative analysis}

The five stages of the Framework analysis method were followed to analyse the data (Ritchie and Spencer, 1994). Data were synthesised and organsised onto a matrix of charts which included four key areas: referral, uptake, continuation and experience. These areas were identified considering the study aims, topic guides and initial examination of the interview and focus group discussions. After organising and synthesising the data onto the charts a descriptive analysis of the themes was conducted, followed by interpretative analysis. This more in-depth, explanatory level of analysis involved identifying patterns, links and associations within the data (Ritchie and Spencer, 1994). Individual interpretative work and interpretative analysis workshops with the project team took place to map, discuss, scrutinize and eventually finalise the emerging themes. The team members involved in data collection and analysis

$(\mathrm{RL}, \mathrm{SN}, \mathrm{JH})$ were multidisciplinary health services researchers with qualitative research experience. Analysis and findings were subject to internal peer-review by the wider study team and externally through seminars, presentations and as part of the reporting process to the study funders.

\section{Ethical approval}

This study received ethical approval from the Wales Research Ethics Committee 5 (REC reference: 15/WA/0419).

\section{Results}

Nine patient interviews (including 5 'completers' and 4 'partial attenders'), one focus group of referring professionals, one focus group of delivering professionals and three GP interviews were conducted. Details of the study sample, including the purposive sampling characteristics, are shown in Table 1. Despite offering telephone and home-based interviews, we were unable to recruit any participants who did not start the programme ('non-uptake' patients). Five themes emerged from the analysis and are discussed below with illustrative quotes. 
Lifestyle management for osteoarthritis

\section{Autonomy affects referral considerations}

Referring professionals differed in their interpretation of the LMP referral criteria and the level of autonomy they applied when making referrals. Some professionals described consistently referring patients with hip or knee OA if they had a BMI over 35. However, others described occasions where they made multiple considerations in their decision to refer. This level of autonomy also appeared to be influenced by an individual's inclination towards abiding by the 'system' and how flexible they perceived the criteria to be.

Clinicians made referrals both electronically and during face-to-face consultations, therefore the ability for referring professionals to take multiple factors into account also differed between individuals. More complex considerations and hence increased autonomy was enabled during a face-to-face appointment. On the other hand, professionals making electronic referrals considered mainly the specific inclusion criteria. For example;

'I go down to where it says $B M I$ and if the $B M I$ is 34.9 I send them to orthopaedics and if it's 35 I send on to lifestyle...I try and make the health service function how [they] want it to function and that's what they want to do. I feel really guilty now...obviously if you are working in an orthopaedic clinic and seeing all these poor people struggling then it is bound to affect you isn't it but I don't see that side of things'. (Referring professional)

I speak to the patient, I look at pain, I look at their quality of life, look at how functional they are and how much it's limited them and how long it's been limiting them for, how long they've been struggling. There is a lot of subjective stuff' (Referring professional)

GPs expressed a higher level of autonomy and benefitted from being able to speak directly to patients. However, this face-to-face interaction sometimes appeared to dissuade GPs from making referrals to the LMP. For example, GPs explained being influenced by their patients' ideas about whether they wanted surgery and how well they felt the individual patient would engage with the programme. GPs also explained how a lack of information about the scheme hindered referral.

'There is some patient pressure when they've decided it's time for them to have replacement surgery, despite what we might have explained to them'. (GP) 
Lifestyle management for osteoarthritis

'I don't know what happens when they get referred for exercise...so it's a bit difficult.' (GP)

\section{Positive views but guilty referrals}

Overall, patients had positive views about the programme, with encouraging comments about content and delivery. The multidisciplinary nature of the LMP was also viewed positively by professionals who particularly valued the whole-person, intensive and functional approach, alongside the ability to utilise expertise from other professionals.

Despite these positive views, tensions were also expressed by referring professionals who explained feelings of guilt when referring to the LMP because they felt they were 'dooming' patients to a longer wait (Referring professional 1). However, they suggested this disincentive could be lessened if patients completing the programme were re-listed further up the waiting list. Professionals also felt that the LMP would benefit from extension of the inclusion criteria and potential re-direction to patients with less severe OA and a lower BMI. Quotes from professionals associated with this theme are shown below.

'The professionals were very efficient, the nutritionist talks were quite helpful, and the exercises were gentle but enough to make you feel like you were getting something out of it'. (Patient completer)

'It's a more holistic approach...it's quite intensive isn't it, I'm quite impressed with that, rather than just sending someone for four weeks and expecting them to change'. (Referring professional)

'When you press that button [to refer to LMP] you do feel a little bit as if you are sending them down the shoot'. (Referring professional)

'...People who have got earlier or moderate osteoarthritis who aren't bad enough for surgery. Now if those were put into the programme, there's a chance that their pain might improve and that they might not need surgery'. (Referring professional)

I would prefer that they were re-slotted, not put back on automatically [at the bottom of the list], but...back into the list at the previous point'... (Delivering professional)

II think if we are looking at mild to moderate, then why are we waiting until they are 35 BMI? Why aren't we getting them in at 30?' (Delivering professional) 
Lifestyle management for osteoarthritis

3. Impersonal referrals encouraged resentful participation

Patients discussed their referral experiences and how this affected participation. An interesting pattern began to emerge, whereby patients who were referred by letter or following an appointment in secondary care described feeling concerned, upset and resentful. For example, one suspected that the LMP was a method of reducing the orthopaedic waiting lists and another expressed how they had taken part in the programme because they felt had no choice. Similarly, delivering professionals also described dealing with occasions when patients had attended feeling upset and resentful about being referred to the LMP.

On the other hand, the 'partial-attenders' interviewed who described being referred initially by their GP and appeared more satisfied with the referral process. However, patients referred by more impersonal methods (i.e. by means of a letter from secondary care) went on to complete the programme, whereas patients who were referred by their GP in a more personal, face-to-face manner only partially completed the programme. One patient 'completer' explained how referral from secondary care meant they viewed the LMP as part of their treatment plan, offering a potential explanation for this pattern. Quotes relevant to this theme are shown below.

'My feeling is that the LMP may be a way of keeping waiting lists down for treatment, perhaps that's true, perhaps it's not, I don't know...I kept going so they wouldn't say that you have not been on the programme so you can't see the specialist'. (Patient completer)

I didn't mind the letter, it was just the wording that I was concerned with, which felt a bit threatening that if I didn't go, I wouldn't get my knee done'. (Patient completer)

'Referral by the consultant made me think to do it as it was part of my treatment'. (Patient completer) 'We do have patients that come and initially be resentful but I just allow them to express that...then they can often move on to engage with it if they're not shut down and they are allowed to say how annoyed they are and "I [the patient] haven't been able to see a consultant". (Professional deliverer)

\section{Varied patient motivations to participate}


Lifestyle management for osteoarthritis

Patients' reasons for initial uptake and motivation to continue with the LMP varied, with both healthorientated (e.g. weight reduction, pain management, improving mobility, strength and fitness) and waiting list-orientated (e.g. seeing a specialist more quickly) reasons for participating.

'Because of my arthritis, I was really struggling...just wasn't coping and was getting bigger and bigger, with worse pressure on my joints'. (Patient partial attender)

I know the background of the exercise, but by doing this LMP I can push up the list of operation a bit more quick'. (Patient completer)

Corresponding with this, GPs explained how they tried to motivate patients to lose weight by emphasising the health benefits of the programme, reminding patients of the opportunity to self-manage and by using 'bargaining techniques' centering on the implications for replacement surgery.

Want to try to keep patients on board so explain that they are unlikely to operate because of their weight, but the patient could try to keep their side of bargain and lose weight, say 2 stone, by then they might put you on the list'. (GP)

\section{The LMP brings practical and psychological delivery challenges}

Practical issues such as the location and timing of the sessions were important to participants, with the cost-free aspect of the LMP reducing a potential barrier for patients. Consistency in delivery was also discussed by delivering professionals and whilst standardisation was viewed as important for monitoring and evaluation purposes, flexibility was valuable when tackling local participation challenges.

It was highlighted that psychological aspects need consideration, with patients suggesting that one-toone sessions could help address this. A patient's readiness to change appeared to be a significant contributing factor to uptake and retention. However, a lack of information and patient-professional discussion at the point of referral may hinder this process, as patients need time and appropriate information in order to consider a lifestyle change.

All professionals and some patients discussed the helpful social impact of the group-based programme, which also played a part in encouraging continued participation after the 32-week programme. However, some patients explained how using the gym in a public environment, especially if there were other fit, young people around, was a source of embarrassment. 
Lifestyle management for osteoarthritis

Delivering professionals discussed how a lack of time to monitor attendance and provide support during the programme and the continuing lifestyle change process was compounded by increasing administrative demands.

Finally, referring professionals explained how they felt further and ongoing evaluation of the LMP would help address the current challenges. Quotes from participants relating to the challenges associated with the LMP are shown below.

If there was a psychological element whether counselling or some sort of element, as well as the exercise, to explore peoples' views and feelings...find out why people struggle to lose weight ...explain why do they have to do this course and how to maintain it'. (Patient partial attender)

'Because they don't actually know what they are there for and so during the consultation it's not only us who are finding out whether they are ready to change its the person themselves'. (Professional deliverer)

'We were talking about the inconsistencies of the schemes before but sometimes that can be a positive thing as well because if something is not working in your area then you can always adapt it, you're not just stuck'. (Professional deliverer)

The more information we have and feedback from it, the more able you are to do an appropriate referral'. (Professional referrer)

'Evaluation is important because there comes a cost with programmes like this... we have to look at what works best and what doesn't'. (GP)

\section{Discussion}

This qualitative study explores the views of a combined exercise, diet and physiotherapy programme designed for people being considered for orthopaedic replacement surgery of the hip or knee. It uses qualitative methods to explore and interpret the views and experiences of patients, professionals and clinicians involved at different stages of the LMP pathway.

Overall, patients and professionals valued the LMP and felt it had good intentions. However, shortcomings were identified, especially with regard to referral criteria and referral processes. More 
Lifestyle management for osteoarthritis

specifically, referring clinicians interpreted the referral criteria differently and perceived varying levels of autonomy in decision-making. Clinicians were also influenced by whether they were triaging electronic referrals or making decisions based on face-to-face consultations with patients. Professionals valued the programme's multidisciplinary nature but felt guilty about delaying patients on the orthopaedic waiting list. They also felt that the programme would be better targeted towards those with less severe OA and lower BMI. Patients referred after consultation with their GP were more satisfied with the referral process than those who received a letter after diversion of their orthopaedic referral during the triage process. Motivation to participate varied according to perceived health gain, position on the waiting list, practical barriers such as location, timing and cost, and readiness to change. There were social benefits of the programme, but also the potential for embarrassment as a result of group-based sessions.

Previous studies have highlighted concerns about time constraints, priority setting during appointments, knowledge and expertise when making referrals (Din et al., 2015). Additionally, patients have demonstrated preferences for triage by experienced clinicians, continued support from a multidisciplinary team (Joseph et al., 2014), social support and supervision (Hendry et al., 2006, Thomas et al., 2008) and a more global assessment of the impact of having OA (Alami et al., 2011). Furthermore, 'being stuck in old habits' and 'emotional baggage' resulting from previous negative experiences have been identified as added psychological barriers to lifestyle change amongst overweight patients (Folling et al. 2015). Taken together, these findings further endorse the multidisciplinary nature of programmes such as the LMP, but also the need to enhance psychological support to help maintain behaviour change.

The current study highlights concerns that patients referred to the LMP may experience extended surgical waiting times as a result of completing the programme. However, whilst non-surgical treatments such as exercise and diet therapy have been shown to be cost-effective for obese patients and patients with OA (Robertson et al., 2014), delaying replacement surgery for severe knee and hip OA is not costeffective (Mather et al., 2014, Mota, 2013). Furthermore, current guidelines recommend that patientspecific factors (including age, sex, smoking, obesity and comorbidities) should not be barriers to referral for joint surgery (National Institute for Health and Care Excellence, 2014). Similar to the findings of the current study, previous research has highlighted that patients do not always receive treatment in line with guidelines or their own preferences (Mitchell and Hurley, 2008), which may lead to 
Lifestyle management for osteoarthritis

dissatisfaction and lower treatment adherence (Selten et al., 2016). In addition and corresponding with the views of the clinicians and professionals in our study, research has shown that health professionals feel OA patients should have early access to self-management opportunities and that provision is lacking for patients who are not candidates for surgery (Mann and Gooberman-Hill, 2011).

The GPs in the current study had made few referrals to the LMP, citing a lack of information about the programme. Interestingly, quantitative findings have identified that clinicians' beliefs in the efficacy of non-surgical treatment is associated with increased referral for such treatments (Hofstede et al., 2016), further advocating the need for research to establish the effectiveness of lifestyle management, alongside appropriate dissemination to increase awareness.

Whilst this study offers valuable insight and suggests areas for improvement, it is important to note that we were only able to interview a small number of patients who completed all or part of the programme, and were unable to capture the views of 'non-uptake' patients. This suggests that more intensive or alternative recruitment methods are required in order to recruit this hard-to-reach group. Similarly, we only recruited a small sample of professionals and clinicians, who also had similar years of experience with the LMP. Therefore, the findings do not represent those of professionals newer to the LMP, GPs who are non-referrers or high-referrers or non-uptake patients. This warrants further investigation.

Implications for practice, policy and research

In light of the findings from this study and those of previous research, consideration of where the programme sits in the management pathway for OA is needed. Firstly, 'lifestyle management' might be better targeted towards rehabilitation for OA patients with less severe functional impairment and lower BMI. Secondly, inviting patients to attend during a consultation in primary care may enhance patient satisfaction. Indeed, patients are now currently referred to the programme primarily by their GP. Nevertheless, it is also important to acknowledge that power imbalances may exist in doctor-patient relationships, and so using techniques that avoid unintentional embarrassment or blame, as well as promoting shared decision-making are also important considerations (Abildsnes et al., 2012, JosephWilliams et al. 2014). Thirdly, a disincentive was that those who successfully completed the scheme, but still required specialist orthopaedic opinion, returned to the bottom of the waiting list. However the 
Lifestyle management for osteoarthritis

pathway has since been modified to remove this disincentive, with patients now joining the waiting list at week 32. Finally, the current findings indicate that with administrative streamlining, enhanced delivery could include personalised goal setting, psychological support and increased follow-up of nonattenders.

More research is needed to determine whether the uptake and retention of programmes such as the LMP can be improved by addressing these recommendations, and to determine which patient groups would benefit most. Finally, the effectiveness and cost-effectiveness of referral to a lifestyle management programme or pathway, compared to usual orthopaedic management should be tested in a randomised controlled trial. 
Lifestyle management for osteoarthritis

\section{References}

Abildsnes, E., Walseth, L.T., Flottorp, S.A. \& Stensland, P.S. (2012). Power and powerlessness: GPs' narratives about lifestyle counselling. The British Journal of General Practice, 62, 596, e160-6.

Alami, S., Boutron, I., Desjeux, D., Hirschhorn, M., Meric, G., Rannou, F. \& Poiraudeau, S. (2011). Patients' and practitioners' views of knee osteoarthritis and its management: a qualitative interview study. PloS one, 6, 5, e19634.

Din, N.U., Moore, G.F., Murphy, S., Wilkinson, C. \& Williams, N.H. (2015). Health professionals' perspectives on exercise referral and physical activity promotion in primary care: Findings from a process evaluation of the National Exercise Referral Scheme in Wales. Health Education Journal, 74, 6, 743-757.

Folling, I.S., Solbjor, M. \& Helvik, A.S. (2015). Previous experiences and emotional baggage as barriers to lifestyle change - a qualitative study of Norwegian Healthy Life Centre participants. BMC Family Practice, 16, 73, DOI: 10.1186/s12875-015-0292-z

Hendry, M., Williams, N.H., Markland, D., Wilkinson, C. \& Maddison, P. (2006). Why should we exercise when our knees hurt? A qualitative study of primary care patients with osteoarthritis of the knee. Family practice, 23, 5, 558-567.

Hofstede, S.N., Marang-van de Mheen, P.J., Vliet Vlieland, T.P., van den Ende, C.H., Nelissen, R.G. \& van Bodegom-Vos, L. (2016). Barriers and Facilitators Associated with Non-Surgical Treatment Use for Osteoarthritis Patients in Orthopaedic Practice. PloS one, 11, 1, e0147406.

Joseph, C., Morrissey, D., Abdur-Rahman, M., Hussenbux, A. \& Barton, C. (2014). Musculoskeletal triage: a mixed methods study, integrating systematic review with expert and patient perspectives. Physiotherapy, 100, 4, 277-289.

Joseph-Williams, N., Edwards, A. \& Elwyn, G. (2014). Power imbalance prevents shared decision making. BMJ (Clinical research ed.), 348, 3178.

Kitzinger, J. (1995) Qualitative Research: Introducing focus groups. BMJ, 311, 299.

Mann, C. \& Gooberman-Hill, R. (2011). Health care provision for osteoarthritis: concordance between what patients would like and what health professionals think they should have. Arthritis care \& research, 63, 7, 963-972.

Mather, R.C.,3rd, Hug, K.T., Orlando, L.A., Watters, T.S., Koenig, L., Nunley, R.M. \& Bolognesi, M.P. (2014). Economic evaluation of access to musculoskeletal care: the case of waiting for total knee arthroplasty. BMC Musculoskeletal Disorders, 15. 22.

Mitchell, H.L. \& Hurley, M.V. (2008). Management of chronic knee pain: a survey of patient preferences and treatment received. BMC musculoskeletal disorders, 9, 123.

Mota, R.E. (2013). Cost-effectiveness analysis of early versus late total hip replacement in Italy. Value in health : the journal of the International Society for Pharmacoeconomics and Outcomes Research, 16, 2, 267-279.

Murphy, S.M., Edwards, R.T., Williams, N., Raisanen, L., Moore, G., Linck, P., Hounsome, N., Din, N.U. \& Moore, L. (2012). An evaluation of the effectiveness and cost effectiveness of the National Exercise Referral Scheme in Wales, UK: a randomised controlled trial of a public health policy initiative. Journal of epidemiology and community health, 66, 8, 745-753.

National Institute for Health and Care Excellence (eds). (2014). Osteoarthritis: care and management in adults. National Institute for Health and Care Excellence: London. 
Lifestyle management for osteoarthritis

Ritchie, J. \& Spencer, L. (1994). Qualitative data analysis for applied policy research. In: A. Bryman \& R. Burgess (eds). Analyzing qualitative data. Routledge: London, 173-194.

Robertson, C., Archibald, D., Avenell, A., Douglas, F., Hoddinott, P., van Teijlingen, E., Boyers, D., Stewart, F., Boachie, C., Fioratou, E., Wilkins, D., Street, T., Carroll, P. \& Fowler, C. (2014). Systematic reviews of and integrated report on the quantitative, qualitative and economic evidence base for the management of obesity in men. Health Technology Assessment, 18, 35, $1-424$.

Selten, E.M., Vriezekolk, J.E., Geenen, R., van der Laan, W.H., van der Meulen-Dilling, R.G., Nijhof, M.W., Schers, H.J. \& van den Ende, C.H (2016). Reasons for treatment choices in knee and hip osteoarthritis: A qualitative study. Arthritis Care \& Research, 68, 9, 1260-7.

Thomas, S.L., Hyde, J., Karunaratne, A., Kausman, R. \& Komesaroff, P.A. (2008). "They all work....when you stick to them": a qualitative investigation of dieting, weight loss, and physical exercise, in obese individuals. Nutrition journal. 7, 34, DOI: 10.1186/1475-2891-7-34 
Lifestyle management for osteoarthritis

Tables

\begin{tabular}{|c|c|c|c|c|}
\hline Patients & Age (range, years) & & Male & Female \\
\hline Completers $(n=5)$ & $46-76$ & & - & 5 \\
\hline Partial-attenders $(n=4)$ & $61-68$ & & 2 & 2 \\
\hline Professionals & $\begin{array}{c}\begin{array}{c}\text { Years of LMP } \\
\text { experience }\end{array} \\
\end{array}$ & $\begin{array}{c}\text { Number of } \\
\text { referrals }\end{array}$ & Male & Female \\
\hline \multicolumn{5}{|l|}{ Referring professionals $(n=8)$} \\
\hline Physiotherapist* & 3.5 months -3 years & $2-4 /$ month & - & 4 \\
\hline Triaging clinician & 3 years & 4/month & 1 & - \\
\hline General practitioner & 3 years & $<1-2 /$ year & 3 & - \\
\hline \multicolumn{5}{|c|}{ Delivering professionals $(n=6)$} \\
\hline Physiotherapist & 2 years & N/A & - & 1 \\
\hline Exercise professional & $2-3$ years & N/A & 3 & - \\
\hline Dietician & 2 years & $\mathrm{N} / \mathrm{A}$ & - & 2 \\
\hline
\end{tabular}

Table 1. Purposive sampling characteristics of patients, referring professionals and delivering professionals. * Note: One of the referring physiotherapists was also involved in delivering the programme. 
Lifestyle management for osteoarthritis

Appendix 1. Topic guides

\section{Topic quide for patients}

Opening and 'ice-breaker'

Names and brief description of how and when you were asked to take part in the lifestyle management programme

\section{$\underline{\text { Key topic areas }}$}

- Experiences and views about being asked to take part in the programme

Feelings about being asked to take part in the lifestyle management programme

Feelings about how the programme was explained

Feelings about who explained the programme

Expectations of the programme

- Experiences and views of the programme

Factors that helped and factors that hindered when taking part in the programme

- Uptake and continuation with the programme

Reasons for continuing the programme

Reasons for discontinuing the programme

Dealing with occasions when participation was difficult

- Important outcomes of the programme

Things that would mean the programme had been successful for you 
Lifestyle management for osteoarthritis

\section{Topic quide for referring professionals, including GPs}

\section{Opening and 'ice-breaker'}

Names and brief description of current job role with regards to the lifestyle management programme and frequency of referrals to scheme.

\section{$\underline{\text { Key topic areas }}$}

- Experiences and views about referring patients to the programme

Experiences of referring patients to the programme

Considerations when referring patients to the programme

Ways of explaining the programme to patients

Expectations relating to the programme

- Experiences of the programme

Helping and hindering factors associated with the programme

- Uptake and continuation with the programme

Methods of dealing with patients who you think may not start or may discontinue with the programme

Tailoring approach for different patient groups

- Important outcomes of the programme

Things that would mean the programme has been successful 
Lifestyle management for osteoarthritis

\section{Topic quide for delivering professionals}

Opening and 'ice-breaker'

Names and brief description of how often you see people who are participating in the scheme.

\section{Key topic areas}

- Experiences and views of being involved in programme delivery

Experiences of delivering the programme to patients

Helping and hindering factors associated with the programme

Expectations relating to the programme

- Experiences of the programme

Helping and hindering factors associated with the programme

- Uptake and continuation with the programme

Methods of motivating patients during the programme

Tailoring delivery approach for different patient groups

Methods of dealing with occasions when patients may discontinue with the programme

- Important outcomes of the programme

Things that would mean the programme has been successful 